\title{
TECHNOLOGY 4.0 FOR BUILDINGS MANAGEMENT: FROM BUILDING SITE TO THE INTERACTIVE BUILDING BOOK.
}

\author{
Eleonora Laurini $^{1 *}$, Marianna Rotilio ${ }^{1}$, Matteo Lucarelli ${ }^{1}$, Pierluigi De Berardinis ${ }^{1}$ \\ ${ }^{1}$ DICEAA, Civil, Construction-Architectural and Environmental Engineering Department, 67100 L'Aquila, Italy - \\ elelaurini@yahoo.it, marianna.rotilio@univaq.it, lucarelli_matteo@virgilio.it,pierluigi.deberardinis@univaq.it
}

\section{Commission VI, WG VI/4}

KEY WORDS: HBIM, technology 4.0, black box, building book, smart building site, Internet of things

\begin{abstract}
:
The main result of the research that we intend to illustrate is the connection between the contents of 4.0 Industry (Ciribini 2018), and the information sharing with BIM design (Lucarelli 2018), through the insertion into a single data container (black storage box), of all the sensors inherent to the entire building process, to monitor the building from the early construction phases and obtain a precise history about it. The goal is to create an "As Built" model flanked by the interactive digital building book, capable of an automatic upgrade depending on the variation of the monitored data during the useful life of the building.

The aim of this project is to exploit the use of IoT (Gabriele 2015), for the data communication to the black box (Smart Monitoring Building Box - SMBBox) installed in the building from the beginning of the construction site, in order to initially monitor the status work progress and safety management on site, and subsequently, thanks to the combination with the BIM model for data management, it will be possible to digitize the physical and functional characteristics of the case study object.

The methodological approach is based on the following steps: BIM modeling; sensor design and installation and data container; data collected updating; "As Built" model creation; Interactive building Drafting. This method is being carried out on a restricted building located in the historic center of L'Aquila, subject to seismic improvement as a result of the damage caused by the 2009 earthquake.
\end{abstract}

\section{INTRODUCTION}

A concrete response to the growing demand for organized management of the construction process on site and safety in the workplace can be achieved through the use of rationalized control and management systems and procedures that involve the use of innovative technologies.

The integration of high-tech systems for data storage and management, such as BIM software (Building Information Modeling), with a series of tools and equipment always present on site (PPE, crane, etc.) equipped with IoT sensors (Internet of things) (Nevado 2018), represents the future of construction in terms of quality of realization, sharing of information, but above all in terms of corporate Facility Management.

If all this is seen on a larger scale, and in situations of complexity, such as in the reconstruction of historic buildings in the municipalities hit by the earthquake, it would allow easier development, but above all control and real-time updating of government procedures that rule the process.

Among these we can include the activity planning or site set-up in the areas of intervention, through the communication of data between the companies involved in the reconstruction, precisely because the more the work is extended, the specific processes need to be optimized in order to increase the overall organization and security.

The study of the state of the art has highlighted a growing interest in the sector, which has led to the development of several lines of research. In general, however, the trend followed is that of rationalizing and automating all in the various sectors. The industry of construction site follows the same direction. One of the tools already used is the SmartSafety platform for construction sites [5]. This platform includes an integrated system for the management of safety in large sites powered by battery, with fully wireless instrumentation and infrastructure that allows locating real-time people and work vehicles via GPS, monitoring PPE and the activities performed, generating danger labels and delivering information to communication devices.

On the other hand, other research areas focus on Smart Equipment, which involves the use of construction site clothing and PPE with innovative technologies both from a material and a technological point of view. Among the Smart DPI there is the Smart Helmet [6], a construction helmet solution developed with BIM technology. It allows real-time and remote trasmission of the project realized in BIM within the construction site or the evaluation of the environment where who wears the smart helmet moves.

$t$ is activated by simply lowering the built-in mask that acts as a real computer containing all the design information related to the building subject of the intervention. One of the purposes in the use of these technological devices is to obtain a smart building book (Solustri 2000) increasingly similar to the "as built" construction, but above all that contains in detail all the materials used inside the building for a

\footnotetext{
* Corresponding author
} 
monitoring and maintenance activity over time of all the features that make it up. To date, the smart building book represents, in fact, one of the most important tools for integrated prevention and safety.

The smart building book has been discussed at many conferences. The National Association of Builders (ANCE), has promoted numerous initiatives for the dissemination of this tool since 2017.

In Italy the smart building book is not yet mandatory, although there have been various attempts, both nationally and regionally, to set it up.

The last Draft Law (n. 2826, 'Measures concerning the protection of the territory and provisions aimed at establishing the building log book, of 10 May 2017), indicated 31 December 2017 as the deadline for the Regions for the adoption of measures to make the Smart Digital book mandatory for all private properties (including the areas of appurtenance and any functional destination), in order to secure our territory (both of the soil and of the building heritage) (engineers cc 2019).

\section{METHODOLOGY}

The research developed proposes the experimentation of a totally smart and innovative construction site that is, above all integrated with a work system supported by the digitalization of different solutions. The integration of the BIM with monitoring sensors will allow the management of the construction, technical-administrative and accounting procedures and activities in compliance with safety requirements (figure 1).

To this end, a methodology has been developed that is based first on the modeling in BIM of the design intervention to be carried out and subsequently, through the installation of the black box on site and of the sensors related to it, the monitoring of the building during the construction phases and use. The methodological approach is therefore based on the following steps (figure 2):

1. BIM modeling

2. sensor design and installation and black box

3. Collected data update

4. "As Built" model creation

5. Drafting of the interactive building log book (Smart Digital Book)

The objective of this project is to exploit the use of the IoT, for data communication to the black box (Smart Monitoring Building Box - SMBBox) installed in the building from the construction site set up, in order to monitor the work progress status and safety management on site, and subsequently, thanks to the combination with the BIM data management model, it will be possible to digitize the physical and functional characteristics of the building object of the intervention.

The research carried out to date concerns the first point of the list referring to BIM modeling, in particular for the management of building site stages on a listed building located in the historic center of L'Aquila, subject to repair and upgrade following the damage caused by the 2009 earthquake (Lucarelli 2018), and part of the second one aimed at the design and installation of the black box and the monitoring sensor system.

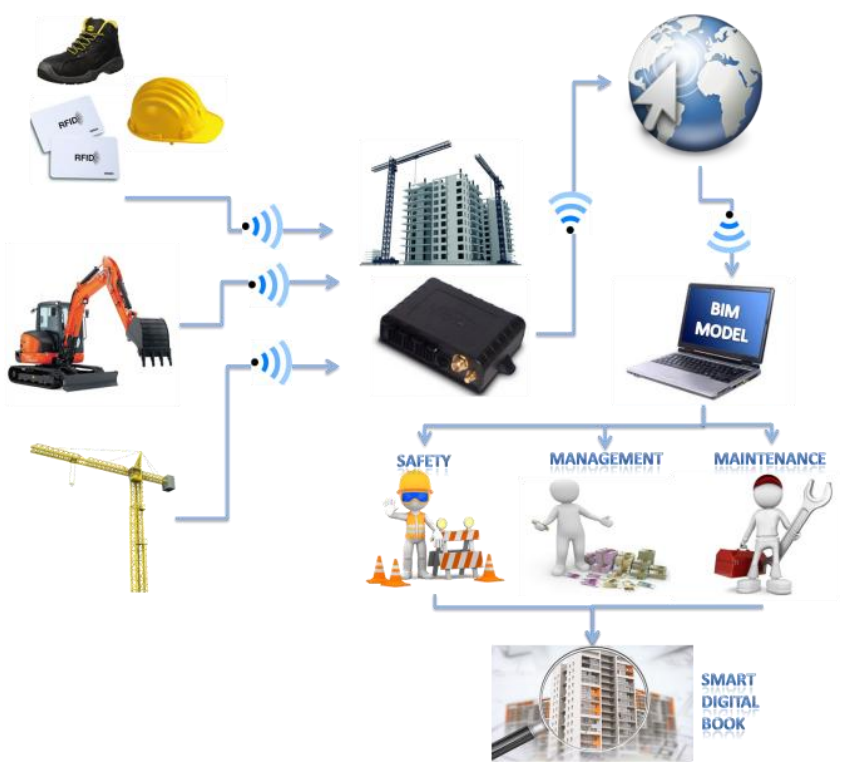

Figure 1: scheme of system operation.

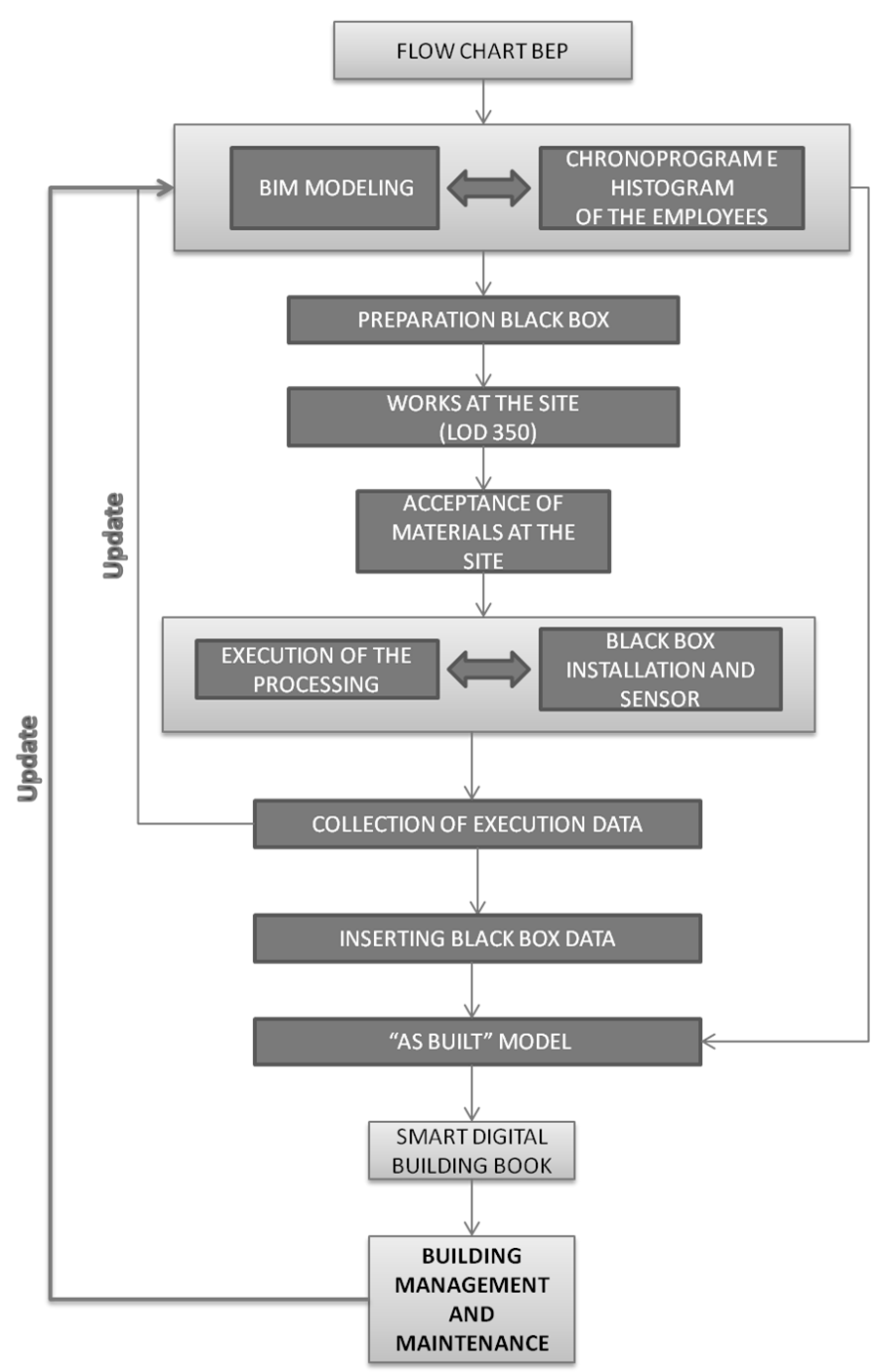

Figure 2: methodological path. 


\section{CASE STUDY}

The building has been the object of a heavy restructuring that has resulted in the seismic structure improvement through consolidation of the horizontal sectors ceilings (Garagnani 2015). For purposes of research, we focused on the study of the consolidation of the brick vaults, which involved a processing with carbon fiber bands.

The study area is identified in the plan below, the portion of slab to be consolidated is on the second floor of the building (figure 3 ).

The construction process of the single phase was analyzed using a BEP, to better interpret all the individual consolidation processes (figure 4).

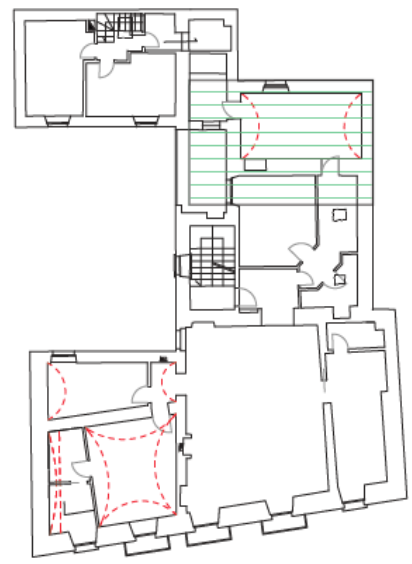

Figure 3: second floor with green identification of the intervention area.
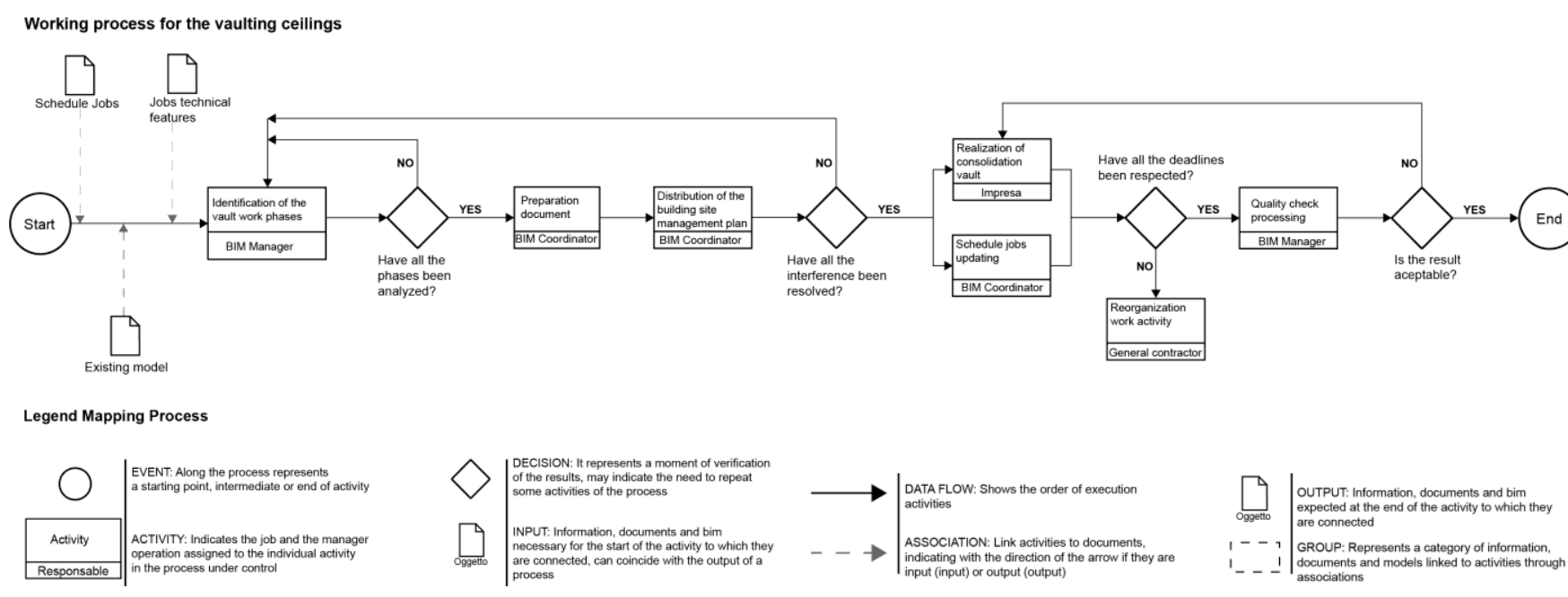

Figure 4: BEP consolidation of the vault.

\subsection{Works analysis}

For the brick vaults consolidation it has been foreseen, after removal of the flooring and of the present filling, the construction of abutments in cement mortar and the application, in the extrados of the vault, of a composite carbon fiber grid made integral with the vault itself from carbon flakes appropriately clamped with anti-shrinkage mortar or epoxy resin, all poached in a hood of fiber-reinforced mortar. The system has also been made integral with the masonry by steel bars inserted in the new blockages in solid bricks. Following the reinforcement, a lightened filling was achieved with expanded clay or light cellular concrete, together with a screed, with a poached electro-welded grid. In addition to work on the vault, also involve inserting the tie rods as an integral part of the consolidation to create the horizontally finished (figure 5).

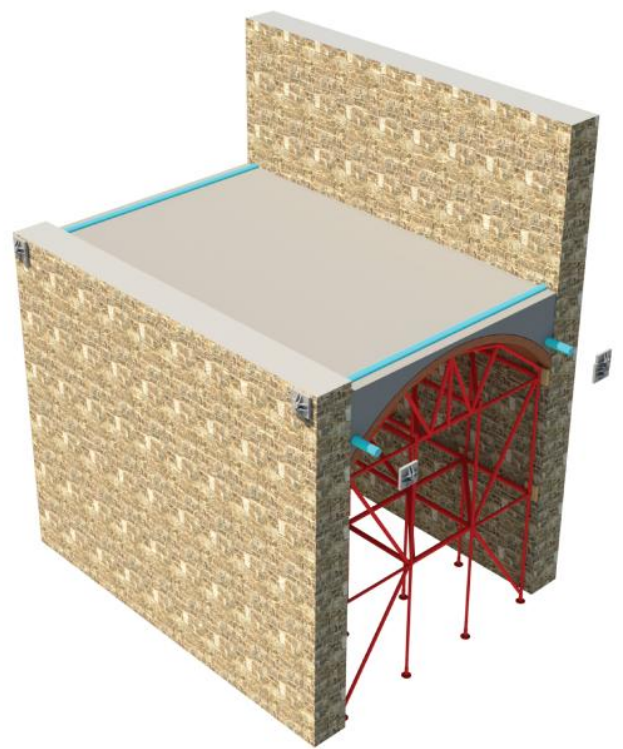

Figure 5: Tie rods insertion model. 

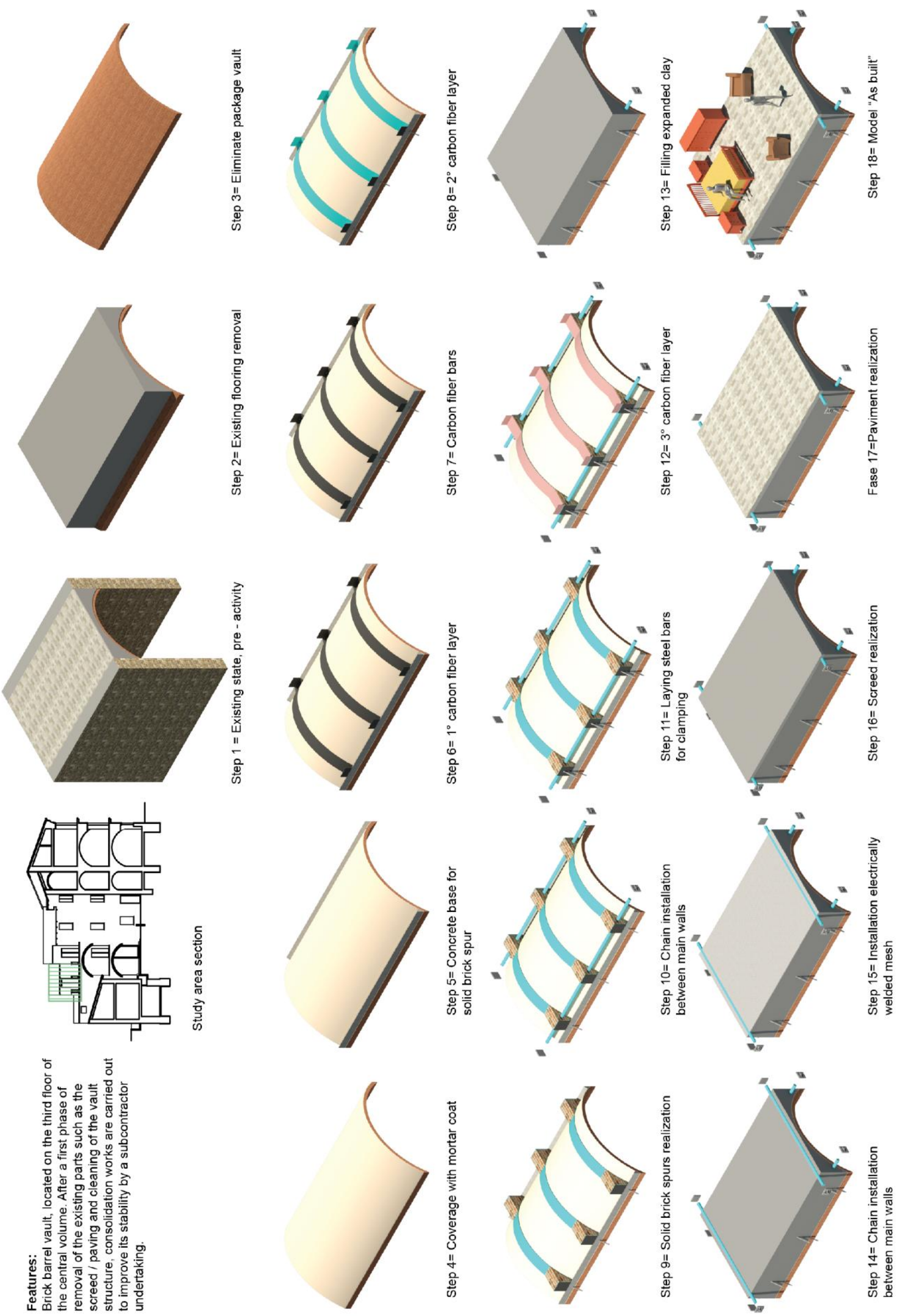

Figure 6: Evolutionary phases of vault consolidation and tie rods insertion modeled in BIM. 


\subsection{Collection of manual and sensorial data.}

Acceptance of materials on the work site is a very complex activity and in recent years the focus on this topic has grown. After passing the acceptance check, all the materials used in the processing are "tabulated" to have a single instrument for collecting information. This collection of data can be carried out for the most part automatically using product traceability through the use of labels with passive Rfid tags. The sense of Rfid's endowment on materials (as well as on means, tools and instruments), is precisely to make them able to describe the origin and characteristics of each product. Once the piece is on the site, the experts can use the RFID technology (figure 7) together with the quality control processes (QA/QC) and the BIM (building information modeling) process, to perform all the investigations and inspections. Finally, these methodologies can provide useful information even when the components are installed. Having the possibility to use such products, the verification on the site can be carried out directly by reading the RFID, recording the data automatically and therefore shortening the process of traceability and quality verification of the products, as part of the process will be absorbed into a single reading operation.
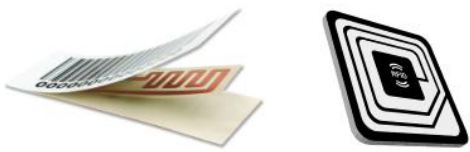

Figure 7: Example of Rfid tag.

The present study provides three levels of verification, two automatic by reading Rfid systems (or barcodes or QrCode), and another manual type. The first two refer to the data provided by the manufacturer and the speaker, which are automatically transferred to the black box connected to the BIM model, the others will be manually entered by the project manager during installation and verification (figure 8 ). For each material used in the processing of the vault, it was therefore essential to include all data, quantities, the origin of the manufacturer's certificates, in order to have a database of all the work, if extended to the entire intervention, of the entire building. The black box therefore represents not only the data collection through sensors, a storage of all the information of the materials, the characteristics of each, but also the day in which the work was carried out and the duration (data available from the gantt chart connected to the BIM model continuously updated).

\begin{tabular}{|c|c|c|}
\hline WORKING: BRICK VAULT CONSOLIDATION \\
\hline $\begin{array}{c}\text { level of } \\
\text { verification }\end{array}$ & survey & features \\
\hline \multirow{2}{*}{ PRODUCER } & \multirow{2}{*}{ with Rfid } & material \\
\cline { 3 - 3 } & & $\begin{array}{c}\text { declaration of } \\
\text { performance }\end{array}$ \\
\cline { 3 - 3 } & & CE marking \\
\hline STOCKIST & with Rfid & furnisher \\
\cline { 3 - 3 } & & quantity \\
\hline \multirow{2}{*}{$\begin{array}{c}\text { CONSTRUCTION } \\
\text { DIRECTOR }\end{array}$} & by hand & date of arrival \\
\cline { 3 - 3 } & & $\begin{array}{c}\text { type and date of } \\
\text { test (if required) }\end{array}$ \\
\hline
\end{tabular}

Figure 8: summary table features of the materials.
The sensors installed and connected to the black box, as well as for security monitoring, will be the type of control of environmental data (indoor and outdoor temperature and humidity, air quality...). These data are fundamental to the control of environmental conditions at the time the work is carried out, especially for some specific activities such as concrete castings, laying of mortars, plasters, etc.

Therefore a station has been installed for the external detection of environmental data (weather station), an air quality sensor and movable temperature and humidity sensors for each work room (figure 9).

The monitoring process, aimed at obtaining the digital building book, is divided into three phases:

- Monitoring ante operam: photograph of the actual state before the changes related to the work that ends with the development of the work site;

- Monitoring during construction: during the production period. Verify the correct execution of the works according to the implementation standards of the materials;

- Post-operation monitoring: it starts just before dismantling the building site and continues during the useful life of the building to monitor the environmental conditions and for the management and maintenance of the plants.

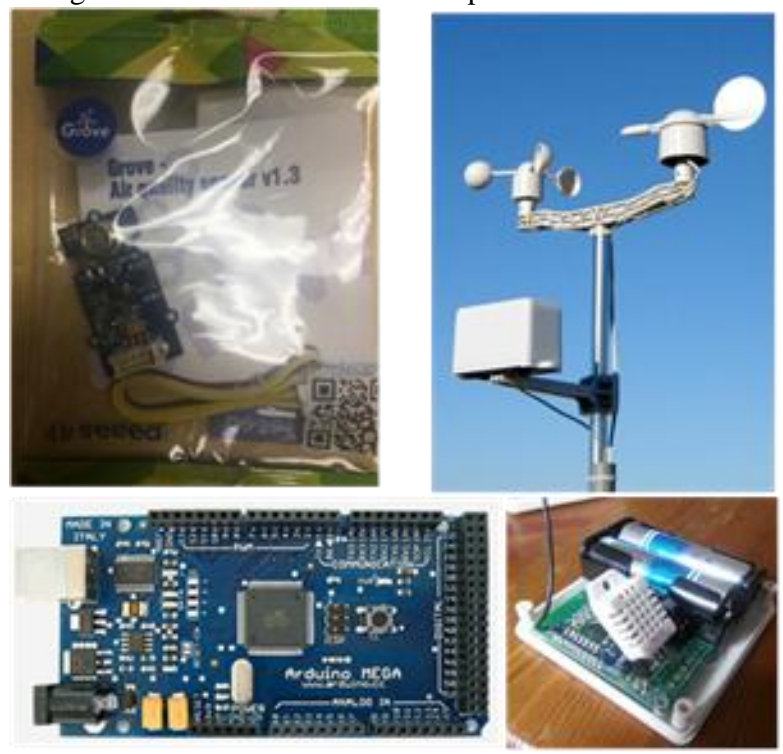

Figure 9: Sensors used: from left to top air quality sensor, weather station, Arduino system, humidity and temperature.

Data collection in the present study refers to monitoring during construction: for each work and for each material, a quality control in the execution was carried out, which will remain in the history of the building and which will highlight the advantages and defects of the realization, as well as to identify materials that, over time, can prove to be harmful and whose use could become prohibited. The sensors for detecting environmental data are also useful to verify the environmental working conditions for safety of the operators on work site.

\section{RESULTS}

As already mentioned, the proposed research has not been completed yet, therefore it has been possible to obtain only partial results. In particular, the first step of the previously analyzed methodology and part of the second one were carried out. For this reason, as it has already been discussed in the previous paragraphs, the first result obtained is inherent in the 
BIM modeling of a complex building aggregate that underwent a post-earthquake restauration of 2009 and seismic structural improvement. However, at present, the black box and the sensor system are being installed to perform the monitoring. The design has already been carried out (an example of a possible graphical interface for the management and maintenance of a frame is shown in Figure 10) and in particular, it was considered appropriate to place the system composed of sensors and black box near to the vault object of intervention. Therefore, a sensor network was created, an infrastructure composed of elements capable of making, processing and communicating measurements to a central point in which the data are elaborated (black box). The design of a Sensor Network involves the management of network protocols for communication with the various sensors, an application necessary for the management and the storage of data, an external interface for the consultation and analysis of data, a database that contains them and a web server with a specific web application.

For the structure of the Sensor Network, several wireless nodes are provided. They are spread in the delimited areas of the work and periodically, they send the data collected by sensors to a collection point (the black box) which manages the network, collects data from the nodes and forwards them to another remote system for secure storage and for further processing provided in the BIM model and in the operating software. Once the system installation is complete, it is possible to proceed with monitoring and updating of the data. The execution of all the methodological steps will allow the achievement of the final result that is a single document that will be present in the building book. Currently, this document is very important in a period where the Italian building heritage must be subjected to important and continuous restructuring and the safety of people is the main objective of any building intervention.

This compiled building book can give us detailed information on the state of health of the buildings (Pesce 2018), to be able to act promptly with a maintenance plan or to facilitate the reconstruction after collapses or damage. Moreover, all the materials used will be cataloged with precision, in order to verify their useful lifetime, but also the ever-changing environmental and human compatibility.

In addition, intending BIM both as a model and as a process, it opens the way to the creation of the building book in digital form. It is particularly difficult in relation to existing buildings because, often, there are a lot of documents and information, absent or outdated drawings, changes that have taken place over the years and a multiplicity of users and functions (Dejaco 2017). This initial situation, combined with the use of BIM and the use of this IoT system, with protocols and rigid schemes of the traditional approach, requires a clear definition of the model requirements to be translated into information attributes associated to the objects and the whole model. The space is an object of the BIM model as much as a structural or architectural component. The information associated with the spaces, as well as with the other BIM model objects, appropriately reworked and integrated with the black box data, contribute to the creation of a constantly updated building book. Especially, in an existing building, we must face a series of problems very different from those that must be faced during planning and construction; among the main ones, it is possible to list the large amount of information to be historicized and the plurality of non-technical users (or anyway not able to use a BIM software) involved in the management. These two problems can be solved by connecting the BIM model of one or more buildings to a database or to building management systems, simplified and accessible to all users, even thanks to simplified applications for mobile devices. Some of these software are already in production such as BMS (Building Management System) and Computer-Aided Facility Management (CAFM) systems (Ingegneri cc 2019).

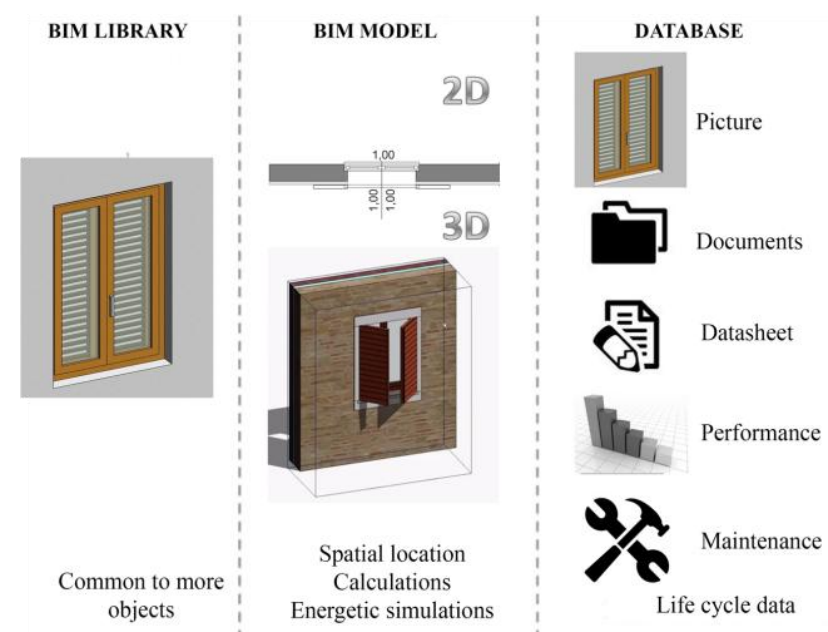

Figure 10: Part of the database with graphic interface for the management and maintenance of a window.

\section{DISCUSSION}

In a digital integration scenario, the ability to monitor data and to process and manage information constitutes the baseline on which to create value. The criticality lies in the fact that over $60 \%$ of buildings in Italy are almost forty years old (ISTAT data for August 2014), and therefore are built with regulations that do not guarantee the current levels of safety and comfort. The inadequacy of the buildings is more highlighted by the continuous seismic events that occurred in Italy in recent years with strong impacts on safety, health and costs to be sustained. Obviously, as in the BIM approach, digitization results a higher cost in a first phase because of investing a lot of time and resources but, it will lead to a simplification and speed up the process in a second phase. The construction system, and the sectors connected to it, achieve a turnover of about $12 \%$ of national employment therefore, the effects of direct or indirect interdependence of the buildings on the economy are significant. Despite this, differently to other sectors, the building trade remains the most traditional and the least digitized one, with direct consequences on productivity and costs of real estate and infrastructure construction and management. It is estimated that the use of smart technologies and related platforms can lead to a reduction in the total cost of the intervention and the management of about 20\%. Such savings and energies could be used, for example, for the recovery of public works, for schools, offices, army barracks, etc., which in many cases are now obsolete and require seismic and energy requalification and they would lead to reduction of management and maintenance costs for national resources.

For years, Italy has found itself inadequate in front of this type of development but, nowadays, we are finally implementing the transition of the building trade to digital, a 4.0 building trade, a path that can play a strategic role to restart its growth, in particular of one of its driving sectors such as construction. From this point of view, the digitalization processes can serve the contracting stations to make the construction works more efficient, the professional technicians optimize the design and 
execution phase, and the construction companies optimize building work site and save resources.

\section{CONCLUSIONS}

In Italy, the request for greater transparency in the knowledge of a building and its state of affairs returns to the limelight whenever a natural or otherwise event occurs, in which one or more buildings suffer damage resulting in loss of human life. The main tool for certifying the status of a building is the building book, a sort of identity card that, over time, provides detailed and summary information on the building from both a technical and administrative point of view. The use of the building book in a design and construction process involves the adoption of Building Information Modeling (BIM) and IoT is the next future (Pesce 2018).

The BIM model is intended as a digital book by defining information, processing it, storing data and connecting to currently available web interfaces.

A further step forward can be taken by the sensors which can be installed on the building from the construction phase, with the purpose of monitoring safety on site, and collecting all the possible data during the construction, in order to have the actual knowledge of materials, installation, installation time. The digitalization of all the documentation of the building and the creation of the digital book of the work and its transmission to the Public Administrations. It will eventually produce a single Big Data Base for the layout of all the buildings, in order to monitor the risk and the vulnerability from the structural point of view, the energy levels and the ordinary and extraordinary maintenance. It will also be possible for Public Administrations to legislate on the minimum maintenance of buildings by users, and to provide incentives for the various types of interventions.

The digitalization of the construction sector, therefore, affects its determining aspects for example: from the point of view of professional performance. It facilitates the sharing of information and helps to develop collaboration platforms and thanks to cloud systems, it allows remote access of all information, simplifying and accelerating all the design and production processes. Following a digital design, the BIM model allows the transfer of a "virtual model" from the designer to the winning company, to the subcontractors and to the owner/user, allowing each involved figure to add specific knowledge to the model. This reduces information losses, increasing the quality of the finished product and helping to reduce waste of time and resources.

In other words, we talk about Facility Management (Jeong 2016), which is the design, implementation and control process through which we can create a quality work environment against minimal economic resources.

It is time for a new paradigm to promote urban regeneration and a real estate re-development of the country because, if an important transformation process has already begun in the industry, the construction sector has to look to the future as well. Smart buildings integrated in a smart country are therefore the first step towards the electric city intended as a set of "smart systems" that act and interact in a preventive manner, which has not only the safety of people as main objective, but also the reduction of land consumption through the safeguarding of our building heritage.

\section{ACKNOWLEDGMENT}

E.L. defined the structure and organization of the article and wrote the article. E.L. and M.R. wrote the results chapter. M.L. elaborated figures 3,4,5,6 during the research development. The research group consisted of all the authors. In particular P.D. was responsible for the scientific research.

The study presented in the article was developed within the research group "Production of the building industry and rational management of the construction process on site", DICEAA, University of Study of L'Aquila.

\section{NOTE}

Figure 10: the image was created by the authors based on a figure from Dejaco M.C., Maltese S., Re Cecconi F., Il fascicolo del fabbricato, Maggioli Editore, febbraio 2017, ISBN: 978-88-916-2178-8.

\section{REFERENCES}

Ciribini A.L.C., 17/05/2018. Dalla Fabbrica 4.0 al Cantiere 4.0: Nuovi Modelli di Business per le Imprese di Costruzioni, , Ingenio web, 17th May 2018.

Lucarelli M., Laurini E., Rotilio M., De Berardinis P. October 2018. Metodo BIM: gestione dei cantieri edilizi nei centri colpiti da calamita' naturali, VI Edizione Convegno ReUso, Messina 11-12-13th. Gangemi Editore, Roma, ISBN: 978-88492-3659-0

ANCE, Manifesto di Federcostruzioni, 4th July 2018.. Edificio 4.0: Costruire digitale per un'Italia più sociale, più sicura, più sostenibile. Proposte per la Rigenerazione Urbana e una Riqualificazione Immobiliare del Paese. Roma,.

Gabriele T., Pantoli L., Stornelli V., Chiulli D., Muttillo M., 2015. Smart power management system for home appliances and wellness based on wireless sensors network and mobile technology, Proceedings of AISEM, p. 1-4, doi:10.1109/AISEM.2015.7066808.

Nevado L., 1th August 2018. Big Data e Internet of things (IoT) nella filiera delle costruzioni, EdilTecnico..

Solustri C., 28 aprile 2000. Il fascicolo del fabbricato. Controllo e sicurezza immobiliare, Carocci, Manuali del progettista, EAN 9788843015917

Ingegneri cc, 15 gennaio 2019. Fascicolo fabbricato BIM. Come gestire le informazioni degli edifici esistenti.

Lucarelli M., Laurini E., De Berardinis P., 2019. 3D and 4D Modeling in building site working control. In 8th International Workshop 3D-ARCH 3D Virtual Reconstruction and Visualization of Complex Architectures. ISPRS Volume XLII2/W9.

Garagnani S., 2015. HBIM nell'esistente storico Potenzialità e limiti degli strumenti integrati nel recupero edilizio. Ingenio Magazine, pp. 3 - 5. ISSN 2307-8928.

Ferrara, A. Feligioni, E., 2016. BIM e Project Management, Dario Flaccovio Editore, pp. 16-25.

Rizzarda C., Gallo G.,2017. La sfida del BIM. Un percorso di adozione per progettisti e imprese. Tecniche nuove, pp. 64-80. 
Pesce A., 7 marzo 2018. Rispunta il fascicolo fabbricato. Ma questa volta in formato digitale, Rubrica online, Studio Pascale news.

Dejaco M.C., Maltese S., Re Cecconi F., febbraio 2017. Il fascicolo del fabbricato, Maggioli Editore, ISBN: 978-88-9162178-8.

Jeong W., Chang S., Son J., Yi J., 2016. BIM-Integrated

Construction Operation Simulation for Just-In-Time Production Management. Sustainability Journal Volume 8 Issue 11. 